\title{
Abscopal effect of radiation on multiple lung metastases of lung adenocarcinoma: a case report
}

\author{
Aoi Kuroda ${ }^{1}$, Takaya Tabuchi ${ }^{2}$, Eri Iwami ${ }^{1}$, Kotaro Sasahara ${ }^{1}$, Tatsu Matsuzaki ${ }^{1}$, Takahiro Nakajima' ${ }^{1}$, Yuki Tsutsumi ${ }^{3}$, \\ Keisuke Eguchi ${ }^{4}$ and Takeshi Terashima ${ }^{1 *}$ (i)
}

\begin{abstract}
Background: Abscopal effect is the out-of-field response to localized irradiation therapy that results in systemic antitumorigenic effects such as the regression of a tumor distant from the target site.

Case presentation: A 76-year-old woman was diagnosed with pulmonary adenocarcinoma (cT1 bNOMO stage IA), and right upper lobectomy was performed in November 2015. The pathological stage was PT1bN2M0 stage IIIA. Genomic analysis revealed an EGFR mutation. Immunohistochemical analysis revealed a programmed death-ligand 1 tumor proportion score of $<1 \%$. The patient was under watchful observation without adjuvant chemotherapy. Multiple mediastinal and right hilar lymph node metastases were found in February 2018. Radiation therapy at a total dose of $60.0 \mathrm{~Gy}$ distributed in 30 fractions was performed over a period of 6 weeks. A computed tomography (CT) scan performed 6 weeks after irradiation therapy showed a reduction in lymph node metastases. However, left hilar and right supraclavicular lymph node metastases and multiple pulmonary metastases were newly observed outside of the irradiation field. A CT scan performed 6 weeks later showed a dramatic complete disappearance of the previously observed pulmonary metastases. No chemotherapy was administered during the period.
\end{abstract}

Conclusion: This was a case of abscopal effect: irradiation of the mediastinum resulted in the disappearance of multiple pulmonary metastases in both lungs.

Keywords: Abscopal effect, Adenocarcinoma, Irradiation, Lung cancer, Pulmonary metastases

\section{Background}

An abscopal effect has been defined as a systemic antitumorigenic effect that results in the regression of a tumor from the irradiated site by localized irradiation therapy. The first abscopal effect was reported by Mole [1], and other cases in several tumor types, including lymphoma, melanoma, and renal cell carcinoma, have since been reported [2]. There have been, however, only a few case reports of abscopal effect in non-small cell lung cancer (NSCLC) [3-8].

Herein, we report a case of lung adenocarcinoma showing complete disappearance of multiple pulmonary metastases after mediastinal irradiation therapy, suggesting an abscopal effect.

\footnotetext{
* Correspondence: terasima@tdc.ac.jp

'Department of Respiratory Medicine, Tokyo Dental College Ichikawa General Hospital, 5-11-13 Sugano, Ichikawa, Chiba 272-0824, Japan

Full list of author information is available at the end of the article
}

\section{Case presentation}

A 76-year-old woman was referred to our hospital because of a nodule in the right upper lobe. The patient had no respiratory symptoms. The computed tomography $(\mathrm{CT})$ scan of the chest revealed a $2.3 \times 1.6 \mathrm{~cm}$ nodule, and the patient was diagnosed with pulmonary adenocarcinoma (cT1bNOM0, stage IA, according to the TNM classification of the Union for International Cancer Control (UICC), 7th edition; cT1cN0M0, stage 1A3, according to the UICC, 8th edition). The patient had no smoking history. Her comorbidities consisted of hypertension and hyperlipidemia. The right upper lobectomy was performed in November 2015, and the pathological stage was pT1bN2M0, stage IIIA. Genomic analysis revealed the epidermal growth factor receptor (EGFR) gene mutation L858R in exon 21. Immunohistochemical analysis revealed a programmed death-ligand 1 (PD-L1)

(c) The Author(s). 2019 Open Access This article is distributed under the terms of the Creative Commons Attribution 4.0 International License (http://creativecommons.org/licenses/by/4.0/), which permits unrestricted use, distribution, and reproduction in any medium, provided you give appropriate credit to the original author(s) and the source, provide a link to the Creative Commons license, and indicate if changes were made. The Creative Commons Public Domain Dedication waiver (http://creativecommons.org/publicdomain/zero/1.0/) applies to the data made available in this article, unless otherwise stated. 
tumor proportion score (TPS) of $<1 \%$. The patient was under watchful observation without adjuvant chemotherapy. Multiple mediastinal and right hilar lymph node metastases were found in February 2018. Radiation therapy alone was selected because the recurrence of the disease was limited to the local region and the patient was 79 years old at the time of recurrence. Radiation therapy amounting to a total dose of $60.0 \mathrm{~Gy}$, distributed in 30 fractions, was performed over a period of 6 weeks. The $3 \mathrm{D}$ radiotherapy-planning technique was used. In the first 4 weeks, $40.0 \mathrm{~Gy}$ was distributed in 20 fractions using opposing anterior-posterior fields (Fig. 1a, b). In the subsequent 2 weeks, an additional 20.0 Gy was distributed in 10 fractions using 10 beams (Fig. 1c, d) for covering multiple mediastinal lymph node metastases but sparing the spinal cord and hilum of the left lung. The planning target volume included multiple mediastinal and right hilar lymph nodes, with a $10 \mathrm{~mm}$ margin to account for microscopic disease, internal moving, and setup errors. The percentage volume of lung receiving a dose of more than 20 Gy (V20) was $29.3 \%$. Static radiotherapy was delivered using a $10 \mathrm{MV} \mathrm{X}$-ray and five fractions per week. A chest CT scan performed 6 weeks after the irradiation therapy showed reduction of the lymph node metastases. However, left hilar and right supraclavicular lymph node metastases and multiple pulmonary metastases were newly observed outside of the irradiation field (Fig. 2). EGFR tyrosine kinase inhibitor (TKI) treatment was planned as a start. Interestingly, a follow-up chest CT scan performed 12 weeks after the completion of irradiation therapy showed complete disappearance of the multiple pulmonary metastases associated with radiation pneumonitis (Fig. 2). However, there was no change in the size of the left hilar and the right supraclavicular lymph node metastases, which was confirmed by 18-fluorodeoxyglucose positron-emission tomography (PET)/CT (Fig. 3a, b). The patient was therefore under watchful observation, without receiving EGFR-TKI treatment. A follow up CT scan performed 6 months after the completion of irradiation therapy showed a slight increase in the size of the lymph node metastases, but no reappearance of multiple pulmonary metastases nodules (Fig. 4). The levels of serum carcinoembryonic antigen (CEA) dropped from $154.5 \mathrm{ng} / \mathrm{mL}$ to $30.9 \mathrm{ng} / \mathrm{mL}$ after the irradiation therapy and further decreased to $6.8 \mathrm{ng} / \mathrm{mL}$ by 3 months post irradiation therapy. The levels, however, increased again to $19.7 \mathrm{ng} /$ $\mathrm{mL}$ at 6 months after completion of the irradiation therapy (Fig. 5). No cytotoxic chemotherapy or EGFR-TKI was given during the period. The number of $\mathrm{CD}^{+}$lymphocytes was $190 / \mu \mathrm{L}$ at 3 months and $356 / \mu \mathrm{L}$ at 4 months after irradiation.
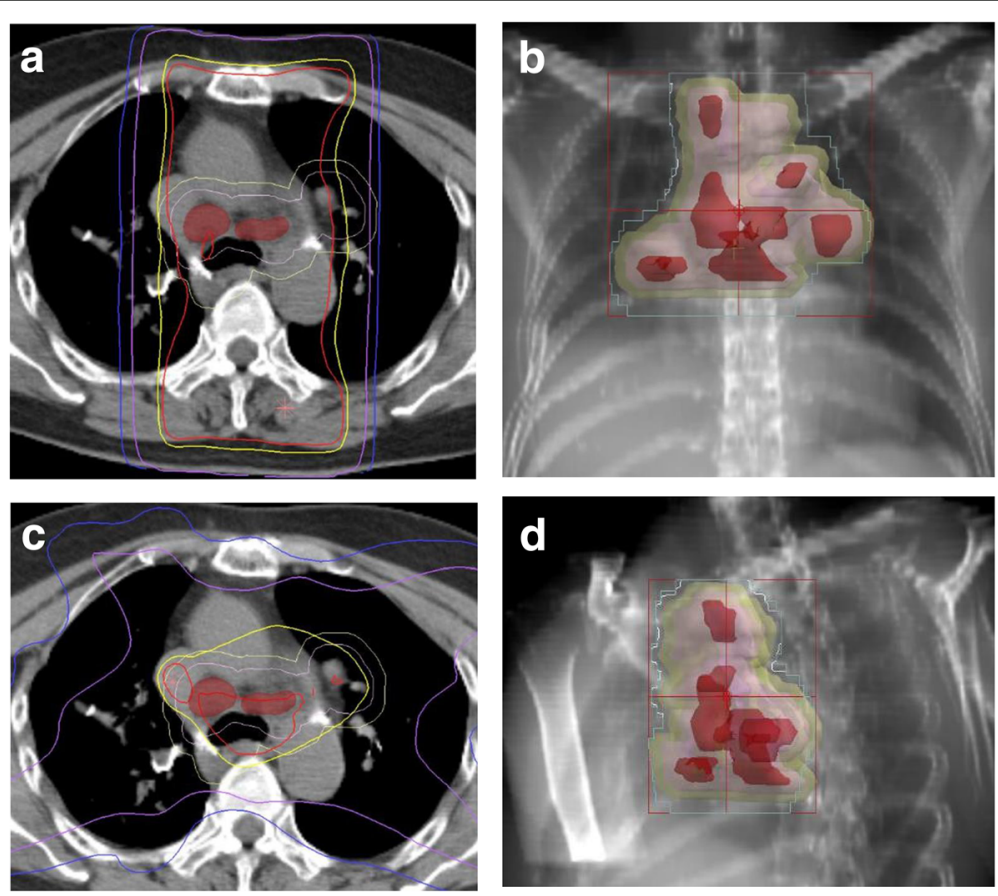

Fig. 1 Radiation therapy to a total dose of $60.0 \mathrm{~Gy}$, distributed in 30 fractions, was performed over a period of 6 weeks. In the first 4 weeks, the treatment was prescribed to the $100 \%$ isodose curve to a total dose of 40.0 Gy distributed in 20 fractions using opposing anterior-posterior fields (a, b). An additional 20.0 Gy was distributed in 10 fractions using 10 beams in the subsequent 2 weeks (c, d). The curves represent $100 \%$ isodose (red), 95\% isodose (yellow), 50\% isodose (purple), and 30\% isodose (blue) (a, c). Gross tumor volume, clinical target volume, and planning target volume are shown in red, pink, and yellow, respectively $(\mathbf{b}, \mathbf{d})$ 


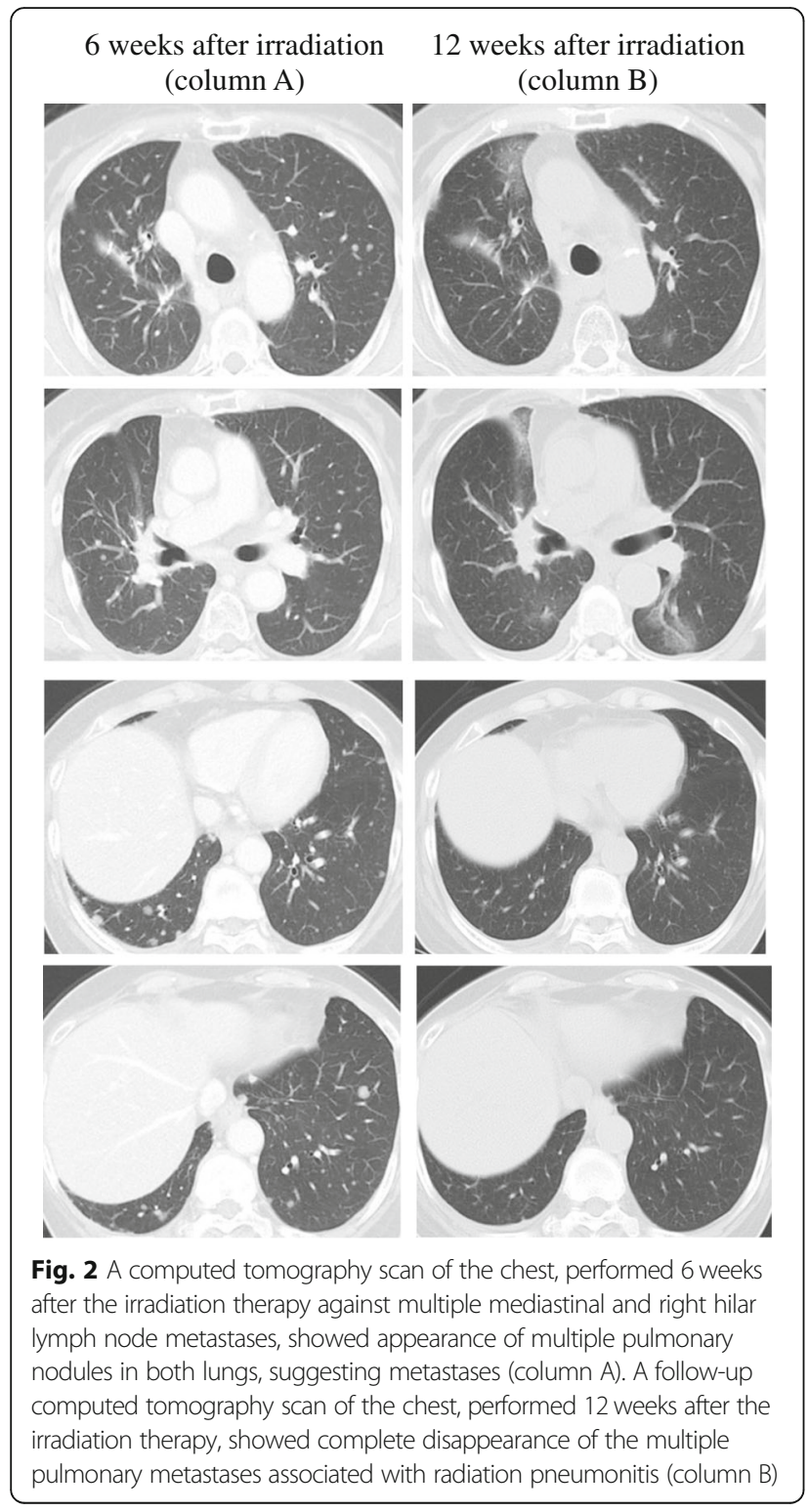

\section{Discussion and conclusions}

In this report, we describe an abscopal effect in a patient with NSCLC. Irradiation of the mediastinal lymph nodes resulted in the complete disappearance of multiple pulmonary metastases. The patient did not receive any other therapy during the period. Although an abscopal effect has been reported in several tumor types [2], clinical reports of it in NSCLC are very rare [3-8]. These reports included cases in which an abscopal response was observed after irradiation and during immune checkpoint inhibitor therapy [3, 4]. In another report, an abscopal response was observed after radiotherapy and during immunotherapy using dendritic cells and cytokine-induced killers in NSCLC [5]. These reports supported the hypothesis that the abscopal effect is likely

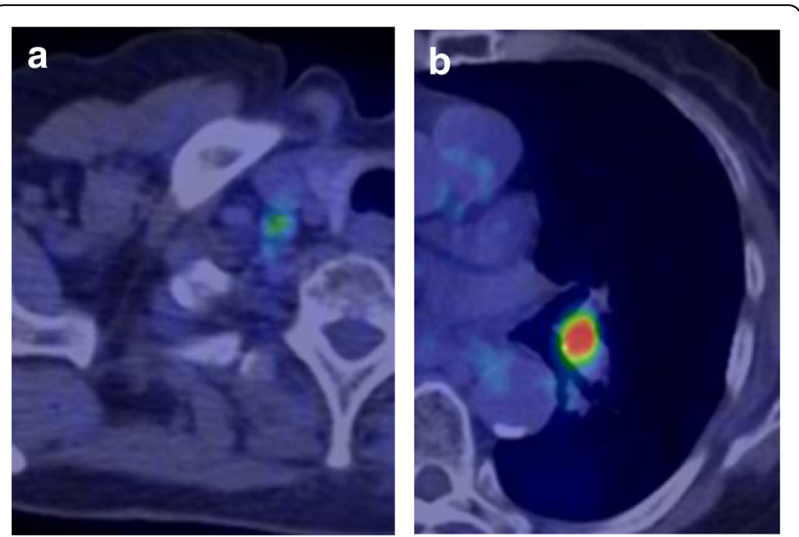

Fig. 3 Positron-emission tomography/computed tomography scan, performed 12 weeks after the irradiation therapy, showed the uptake of 18-fluorodeoxyglucose in the right supraclavicular (a) and the left hilar (b) lymph nodes

mediated by the immune system. Local irradiation-induced direct tumor destruction is speculated to induce the release of circulating tumor antigens and then elicit an inflammation cascade that can activate antigen-presenting cells, which may then mediate an augmented immune response against malignant lesions that express similar tumor antigens in the out-of-target sites. Compared with previous reports in NSCLC, the case presented herein is extremely rare in the sense that no immunotherapy or immune checkpoint inhibitor was given during the course. In other words, a pure abscopal effect was documented in this case.

The present case provides important insight regarding the time when an abscopal effect occurs and for how long the effect is maintained. A literature review reported that abscopal responses occurred after 1-24 months (median 5 months), and the relapse-free time was maintained for 3-39 months (median 13 months) [9]. In the present case, the time to the documented abscopal effect was 3 months, which is consistent with the reported time; however, we could not determine the duration of the effect, because there was no reappearance of multiple pulmonary metastases nodules in spite of a slight increase in the size of lymph node metastases and in the serum CEA levels after 6 months. $\mathrm{CD}^{+} \mathrm{T}$ lymphocytes have been demonstrated to play a key role in the abscopal effect [10-12]. Systemic lymphocytopenia is known to be induced by local radiotherapy, and it usually persists for several months. It is thought that the function, rather than the number of $\mathrm{CD}^{+}$lymphocytes in peripheral blood is important in this phenomenon. On the other hand, it might be possible that the number of tumor-infiltrating $\mathrm{CD}^{+} \mathrm{T}$ lymphocytes is the most significant factor. In the present case, the number of $\mathrm{CD}^{+}$lymphocytes was low when the abscopal effect was documented and high when the regrowth of 


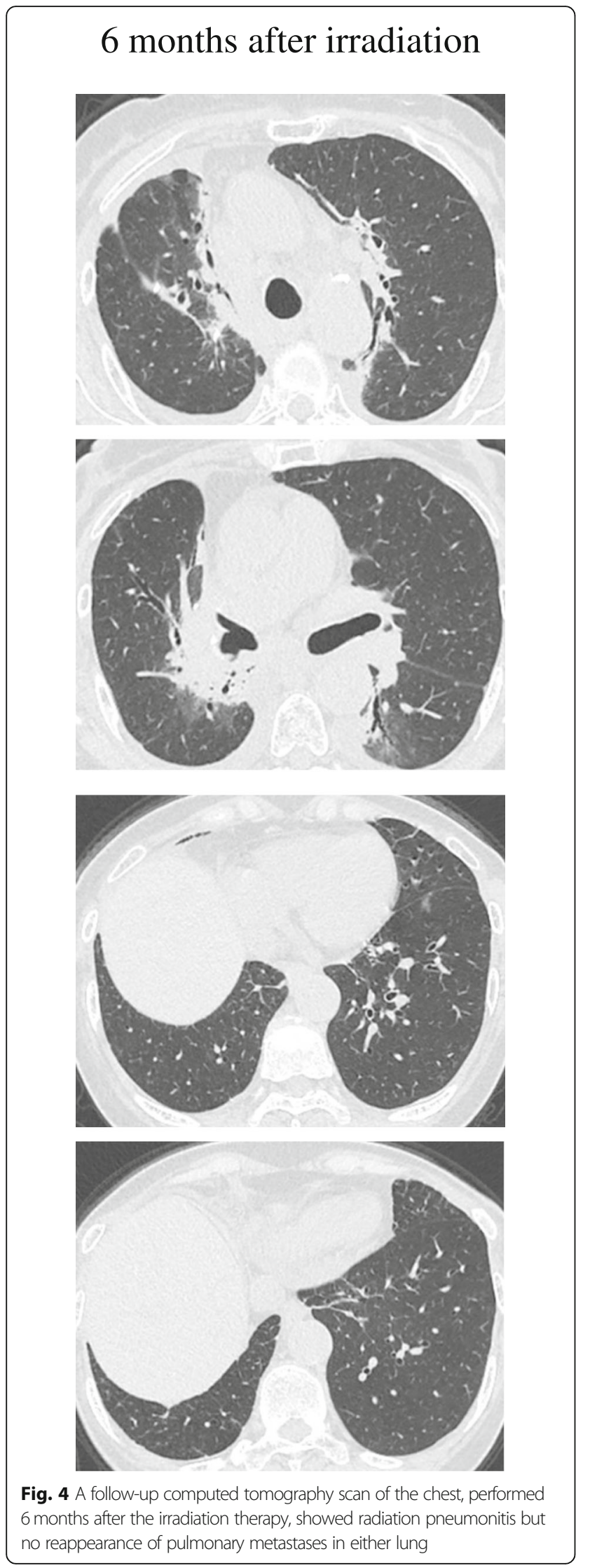

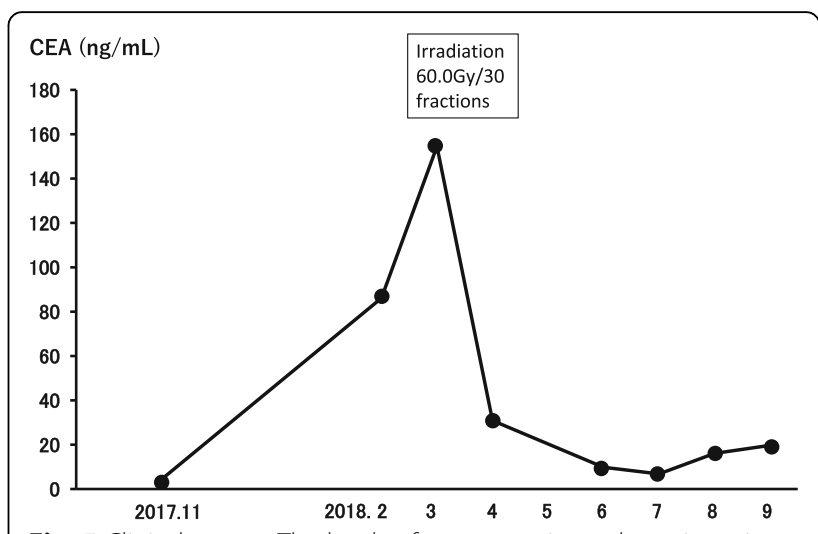

Fig. 5 Clinical course. The levels of serum carcinoembryonic antigen (CEA) dropped from $154.5 \mathrm{ng} / \mathrm{mL}$ to $30.9 \mathrm{ng} / \mathrm{mL}$ after the irradiation therapy and further decreased to $6.8 \mathrm{ng} / \mathrm{mL}$ at 3 months post treatment; however, the levels increased again to $19.7 \mathrm{ng} / \mathrm{mL}$ at 6 months after completion of the irradiation therapy

lymph node metastases and the increase in tumor marker levels was observed.

It should be emphasized that TPS was less than $1 \%$ in this case. The axis of PD-L1 and its cognate receptor programmed cell death protein 1 (PD-1) on the surface of $\mathrm{T}$ cells is known as a $\mathrm{T}$ cell-inhibiting signaling pathway. A possible explanation for the abscopal effect in the present case is that there was little inhibition by the PD-1/PD-L1 pathway on anti-tumor T cell function.

The lung adenocarcinoma in the present case harbored the EGFR mutation L858R in exon 21. There has been one case report which showed an abscopal effect in a patient with NSCLC that harbored the exon 19 deletion and exon $20 \mathrm{~T} 790 \mathrm{M}$ mutations [5]. Because the number of reported cases in which an abscopal effect was observed in NSCLC is extremely low, it is not possible to conclude whether there is a higher likelihood of an abscopal effect occurring in lung cancer that harbors driver mutations.

The limiting factor in this study is that no pathological confirmation of the metastatic pulmonary nodules was obtained. Moreover, it is difficult to speculate why an abscopal effect was observed in the multiple pulmonary nodules, but not the lymph node metastases. However, it is not rare that cytotoxic chemotherapy or EGFR-TKI therapy is effective in some tumor sites but not in others. Size, environment, recruitment of immune cells, and vascularity of the malignant lesion are all factors that contribute to the differences in tumor progression.

Clinical trials have shown that immunotherapy may enhance abscopal effects [13]. Recently, administration of a PD-L1 inhibitor after concurrent chemoradiotherapy for stage III NSCLC has shown a clinical effect [14]. The information obtained from our case provides 
important insight into when and for how long the immunotherapy should be administered to get the most benefit out of an abscopal effect.

In conclusion, we report a case of lung adenocarcinoma showing an abscopal effect resulting in complete disappearance of multiple pulmonary metastases after mediastinal irradiation therapy.

\section{Abbreviations}

CEA: Carcinoembryonic antigen; CT: Computed tomography;

EGFR: Epidermal growth factor receptor; NSCLC: Non-small cell lung cancer; PD-1: Programmed cell death protein 1; PD-L1: Programmed death-ligand 1; PET: Positron-emission tomography; TKI: Tyrosine kinase inhibitor; TPS: Tumor proportion score; UICC: Union for International Cancer Control

\section{Funding}

The authors declare that no funding was received for this study.

\section{Availability of data and materials}

All data generated or analyzed during this study are included in this published article.

\section{Authors' contributions}

AK contributed to treatment decisions, the collection of clinical data, data analysis, and writing the manuscript. TTabuchi, El, KS, TM, TN, and TTerashima contributed to the interpretation of the clinical data and chest images. YT contributed to the radiation therapy. KE contributed to the surgical treatment. All authors have read and approved the final manuscript.

\section{Ethics approval and consent to participate}

Not applicable.

\section{Consent for publication}

Written informed consent was obtained from the patient for publication of this case report and any accompanying images.

\section{Competing interests}

The authors declare that they have no competing interests.

\section{Publisher's Note}

Springer Nature remains neutral with regard to jurisdictional claims in published maps and institutional affiliations.

\section{Author details \\ 'Department of Respiratory Medicine, Tokyo Dental College Ichikawa General Hospital, 5-11-13 Sugano, Ichikawa, Chiba 272-0824, Japan. ${ }^{2}$ Department of Internal Medicine, Tokyo Dental College Ichikawa General Hospital, 5-11-13 Sugano, Ichikawa, Chiba 272-0824, Japan. ${ }^{3}$ Department of Radiology, Tokyo, Dental College Ichikawa General Hospital, 5-11-13 Sugano, Ichikawa, Chiba 272-0824, Japan. ${ }^{4}$ Department of Surgery, Tokyo Dental College Ichikawa General Hospital, 5-11-13 Sugano, Ichikawa, Chiba 272-0824, Japan.}

Received: 21 November 2018 Accepted: 1 April 2019

Published online: 08 April 2019

\section{References}

1. Mole RH. Whole body irradiation_radiobiology or medicine? Br J Radiol. 1953;26:234-41.

2. Brix N, Tiefenthaller A, Anders H, Belka C, Lauber K. Abscopal, immunological effects of radiotherapy: narrowing the gap between clinical and preclinical experiences. Immunol Rev. 2017;280:249-79.

3. Golden EB, Demaria S, Schiff PB, Chachoua A, Formenti SC. An abscopal response to radiation and ipilimumab in a patient with metastatic nonsmall cell lung cancer. Cancer Immunol Res. 2013;1:365-72.

4. Britschgi C, Riesterer O, Burger IA, Guckenberger M, Curioni-Fontecedro A. Report of an abscopal effect induced by stereotactic body radiotherapy and nivolumab in a patient with metastatic non-small cell lung cancer. Radiat Oncol. 2018;13:102.
5. Cong Y, Shen G, Wu S, Hao R. Abscopal regression following SABR for nonsmall-cell-lung cancer: a case report. Cancer Biol Ther. 2017:18:1-3.

6. Siva S, Callahan J, Macmanus MP, Martin O, Hicks RJ, Ball DL. Asbcopal effects after conventional and stereotactic lung irradiation of non-small-cell lung cancer. J Thorac Oncol. 2013;8:e71-2.

7. Hekimoglu E, Kara HV, Demirkaya A, Turna A. Vanishing a primary lung carcinoma following irradiation of cranial metastasis: "the abscopal effect". Turk J Thorac Cardiovasc Surg. 2017;25:294-7.

8. Rees GJG, Ross CMD. Abscopal regression following radiotherapy for adenocarcinoma. Br J Radiol. 1983;56:63-6.

9. Reynders K, Illidge T, Siva S, Chang JY, De Ruysscher D. The abscopal effect of local radiotherapy: using immunotherapy to make a rare event clinically relevant. Cancer Treat Rev. 2015;41:503-10.

10. Tang C, Welsh JW, De Groot P, Massarelli E, Chang JY, Hess KR, et al. Ipilimumab with stereotactic ablative radiation therapy: phase I results and immunologic correlates from peripheral T cells. Clin Cancer Res. 2017;23:1388-96.

11. Pilones KA, Kawashima N, Yang AM, Babb JS, Formenti SC, Demaria S. Invariant natural killer $T$ cells regulate breast cancer response to radiation and CTLA-4 blockade. Clin Cancer Res. 2009;15:597-606.

12. Wang R, Zhou T, Liu W, Zuo L. Molecular mechanism of bystander effects and related abscopal/ cohort effects in cancer therapy. Oncotarget. 2018;9: 18637-47.

13. Liu Y, Dong Y, Kong L, Shi F, Zhu H, Yu J. Abscopal effect of radiotherapy combined with immune checkpoint inhibitors. J Hematol Oncol. 2018;11:104.

14. Antonia SJ, Villegas A, Daniel D, Vicente D, Murakami S, Hui R, et al. Durvalumab after chemoradiotherapy in stage III non-small-cell lung cancer. New Engl J Med. 2017;377:1919-29.

\section{Ready to submit your research? Choose BMC and benefit from:}

- fast, convenient online submission

- thorough peer review by experienced researchers in your field

- rapid publication on acceptance

- support for research data, including large and complex data types

- gold Open Access which fosters wider collaboration and increased citations

- maximum visibility for your research: over $100 \mathrm{M}$ website views per year

At BMC, research is always in progress.

Learn more biomedcentral.com/submissions 